Proceedings of the International Symposium on Physics of Materials (ISPMA 14), September 10-15, 2017, Prague

\title{
Application of Mechanical Alloying in Synthesis of Intermetallics
}

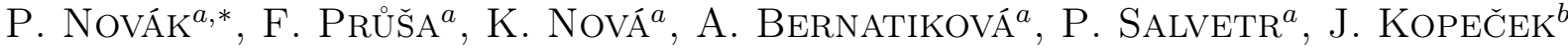 \\ AND P. HAUŠILD ${ }^{c}$ \\ ${ }^{a}$ University of Chemistry and Technology, Prague, Department of Metals and Corrosion Engineering, \\ Technická 5, 16628 Prague 6, Czech Republic \\ ${ }^{b}$ Institute of Physics of the ASCR, v.v.i., Na Slovance 2, 18221 Prague 8, Czech Republic \\ ${ }^{c}$ Czech Technical University in Prague, Faculty of Nuclear Sciences and Physical Engineering, \\ Department of Materials, Trojanova 13, 12000 Prague 2, Czech Republic
}

\begin{abstract}
Mechanical alloying is an interesting method of direct synthesis of various kinds of compounds and preparation of solid solutions using pure elemental powders by high-energy milling. In this paper, the modified process of mechanical alloying, which was developed at UCT Prague, is applied for the synthesis of intermetallics. This process - ultra-high energy mechanical alloying — uses extremely high ball-to-powder ratio (50-70:1), thus enabling very high degree of deformation of the powders, as well as the friction. Due to these effects, the temperatures up to $700{ }^{\circ} \mathrm{C}$ can be probably achieved locally for a short period. It enables to initiate the same chemical reactions between metallic powders as in self-propagating high-temperature synthesis. This study compares the ultra-high energy mechanical alloying with self-propagating high-temperature synthesis in selected alloy systems $(\mathrm{Fe}-\mathrm{Al}, \mathrm{Ni}-$ $\mathrm{Ti}, \mathrm{Fe}-\mathrm{Al}-\mathrm{Si}$ ) in order to explain the formation of intermetallics in this innovative process.
\end{abstract}

DOI: 10.12693/APhysPolA.134.720

PACS/topics: 61.66.Dk, 61.05.cp

\section{Introduction}

Mechanical alloying has been established as a process for materials preparation in 1980's. The process consists in high energy milling of powder mixtures, where the phase composition changes from individual elemental powders to solid solutions, chemical compounds or amorphous materials [1-5]. Mechanical alloying is carried out by high energy milling in various kinds of mills, where the ball mill is the most common one. During mechanical alloying, the following stages happen [3]:

- Joining of particles by plastic deformation. During this stage, typical lamellar microstructure is formed and powder particle size increases. Deformation strengthening occurs as a result of plastic deformation.

- Crushing of particles. Due to deformation strengthening, the ductility of the particles decreases and it leads to a fracture.

- Formation of solid solutions and intermetallics. During milling, solid solutions or intermetallics can occur. It is believed that the changes happen mostly due to high kinetic energy achieved by milling, but the formation of intermetallics as a result of milling was not satisfactorily explained yet.

The process of mechanical alloying lasts very long, usually $20-100 \mathrm{~h}$, which is also its main disadvantage.

*corresponding author; e-mail: panovak@vscht.cz
Authors developed the ultra-high energy mechanical alloying process, which enables to obtain intermetallics in $1-2 \mathrm{~h}$ [5]. It has been achieved by applying extremely high ball-to-powder ratio (50-70:1), high rotational velocity (minimum $400 \mathrm{rpm}$ ) and absence of any processing fluids [6].

Previous research of the authors on self-propagating high-temperature synthesis (SHS) of various intermetallics proved that the rapid reactions are initiated at the temperature between 600 and $1000^{\circ} \mathrm{C}$, depending on the alloy system. Below the initiation temperature of the SHS reaction, the diffusion-controlled slow formation of intermetallics has been found far below the initiation temperature (e.g. at $500-650^{\circ} \mathrm{C}$ in $\mathrm{Ni}-\mathrm{Ti}$ system, where SHS is initiated at more than $900^{\circ} \mathrm{C}$ ) during long-term annealing after 24-48 h [7].

When one compares the mechanical alloying with hightemperature synthesis of intermetallics, the conventional mechanical alloying seems to be similar to the slow diffusional formation of intermetallics, while the innovative ultra-high energy mechanical alloying has some similarities with SHS. Therefore, the hypothesis is that the formation of intermetallics in mechanical alloying is driven mainly by the increase of the temperature of the powder during the process resulting from friction, rather than by the transformation of the kinetic energy of the balls to the deformation energy. This study compares the ultrahigh energy mechanical alloying with SHS in several alloy systems in order to explain the formation of intermetallics in this innovative process. For this purpose, the alloy systems, where SHS reaction proceeds on the interface between solid particles and melt ( $\mathrm{Fe}-\mathrm{Al})$, two 
kinds of solid particles (Ni-Ti) and two solids and one liquid phase $(\mathrm{Fe}-\mathrm{Al}-\mathrm{Si})$ were selected in this work.

\section{Experimental}

In this paper, selected powder mixtures $(\mathrm{Fe}-\mathrm{Al}, \mathrm{Ni}-\mathrm{Ti}$, $\mathrm{Fe}-\mathrm{Al}-\mathrm{Si}$ ) were subjected to ultra-high energy mechanical alloying under the conditions optimized in our previous paper dealing with the synthesis of intermetallics [6]:

- milling duration: 120-240 min,

- change of rotation direction each $30 \mathrm{~min}$,

- rotation speed: $400 \mathrm{rpm}$,

- atmosphere: argon

- powder batch: $5 \mathrm{~g}$

- ball-to-powder weight ratio: 70:1.

For the mechanical alloying, the following elemental powders were applied: iron (purity 99.9\%, particle size < $44 \mu \mathrm{m}$, supplied by Strem Chemicals), aluminium (purity $99.7 \%$, particle size $<44 \mu \mathrm{m}$, supplied by Strem Chemicals), silicon (purity 99.5\%, particle size $<44 \mu \mathrm{m}$, supplied by Alfa Aesar), nickel (particle size $<10 \mu \mathrm{m}$, > $99.8 \%$ purity, supplied by Merck), and titanium (particle size $<100 \mu \mathrm{m},>99.5 \%$ purity, supplied by PENTA). Milling was carried out without lubrication agent. For the comparison, mechanical alloying was carried out in the same mill with the addition of ethanol and also in Retsch EMAX mill. This new kind of milling device was designed to enable long-term operation without overheating of the batch. Therefore it is equipped with cooling of the walls and elliptical design of the milling vessel, which minimizes the sliding of the balls on the wall.

Phase composition was identified by X-ray diffraction analysis (XRD) using a PANalytical X'Pert Pro X-ray diffractometer.

\section{Results and discussion}

\subsection{Fe-Al system}

$\mathrm{Fe}-\mathrm{Al}$ system represents the mixture of powders, where the SHS reaction proceeds on the interface between solid iron and molten aluminium when high heating rates are applied [8]. Ultra-high energy mechanical alloying was tested on three alloys (in wt\%): FeAl25, FeAl35 and FeAl55. Under the applied conditions (milling duration of $2 \mathrm{~h}$, rotational velocity $400 \mathrm{rpm}, \mathrm{FeAl}$ phase was successfully prepared when the content of aluminium in the powder mixture was $35 \mathrm{wt} \%$ (Fig. 1). Lower aluminium amount (25 wt\%) leads to the formation of disordered solid solution of aluminium in iron, even though the $\mathrm{FeAl}$ phase could be expected according to the equilibrium Fe$\mathrm{Al}$ diagram [9]. These results show that mechanical alloying strongly increases the solubility of aluminium in iron from the equilibrium value of nearly $15 \mathrm{wt} \%$ to more than $25 \mathrm{wt} \%$. FeAl55 alloy (in wt\%) was composed of expected $\mathrm{Fe}_{2} \mathrm{Al}_{5}$ phase with the admixture of $\mathrm{FeAl}_{3}$, same as in previous experiments with SHS process [8].

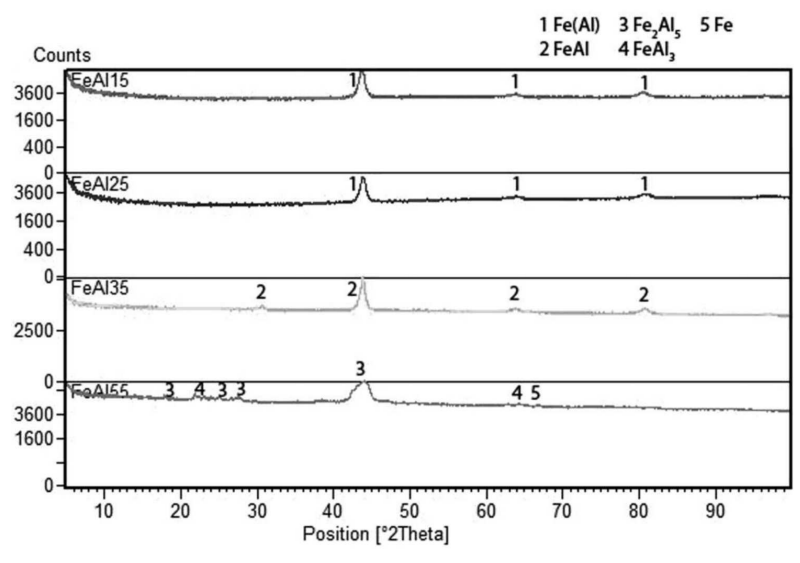

Fig. 1. XRD patterns of mechanically alloyed $\mathrm{Fe}-\mathrm{Al}$ powders (composition of powders given in wt\%), duration 120 min.

The evolution of the phase composition of FeAl55 alloy with the mechanical alloying process duration is presented in Fig. 2. It was found that the $\mathrm{Fe}_{2} \mathrm{Al}_{5}$ intermetallic phase is formed directly from iron and aluminium powders together with the $\mathrm{FeAl}_{3}$ phase. The same phases' formation sequence has been observed previously for the SHS process [8]. However, the FeAl ordered phase formed without any transient phase in FeAl35 alloy (Fig. 1). On the other hand, when the preparation of FeAl phase was tested by SHS from iron and aluminium compressed powder mixture, $\mathrm{Fe}_{2} \mathrm{Al}_{5}, \mathrm{FeAl}_{2}$ and $\mathrm{FeAl}_{3}$ phases arose as transient phases and $\mathrm{FeAl}$ phase was obtained only in a small amount $[8,10]$. These phases are finally transformed to $\mathrm{FeAl}$ after long-term annealing, but direct formation of $\mathrm{FeAl}$ phase was found to be impossible [8]. It shows that the mechanism of formation of intermetallics in $\mathrm{Fe}-\mathrm{Al}$ system during mechanical alloying is different from the thermally activated reactions during annealing of blended powders. It is probably caused by the fact that in SHS the phases form mostly on the interface between solid $\mathrm{Fe}$ and molten $\mathrm{Al}$, while in mechanical alloying the reaction proceeds completely in solid state.

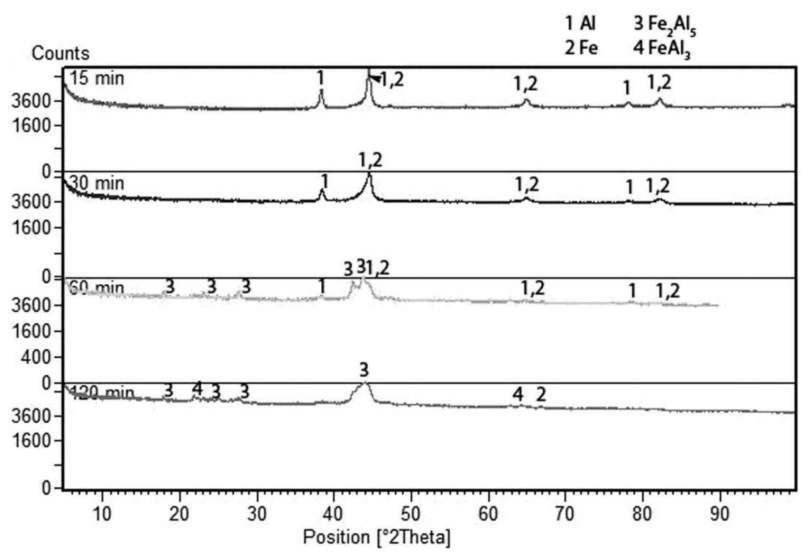

Fig. 2. XRD patterns of mechanically alloyed FeAl55 powder mixture (composition of powders given in wt\%) vs. milling duration. 


\section{2. $N i-T i$ system}

$\mathrm{Ni}-\mathrm{Ti}$ system represents here a mixture of powders, where the SHS reactions are initiated on between two solid phases. The mechanical alloying of $\mathrm{Ni}-\mathrm{Ti}$ powder mixture results in formation of $\mathrm{Ti}_{2} \mathrm{Ni}$ phase which reacts further with nickel in order to form NiTi phase (Fig. 3). Because $\mathrm{Ti}_{2} \mathrm{Ni}$ forms preferentially, it retains partially in the structure of the product. For the comparison, research in reactive sintering revealed that the $\mathrm{Ti}_{2} \mathrm{Ni}$ phase forms when the temperature exceeds $500^{\circ} \mathrm{C}$, while the NiTi shape memory phase starts to form at the temperatures over $630^{\circ} \mathrm{C}$ [7]. The SHS reaction is initiated at the temperature of $882^{\circ} \mathrm{C}$, i.e. the $\alpha \rightarrow \beta$ transformation temperature of titanium. Below the temperatures 500 and $630{ }^{\circ} \mathrm{C}$, the formation of $\mathrm{Ni}-\mathrm{Ti}$ phases was not detected even after days of annealing [11]. From this fact it can be presumed that the local temperature of the powder during ultra-high mechanical alloying exceeded these values and reaches minimum $630^{\circ} \mathrm{C}$. Since it is possible to measure only the temperature of the milling atmosphere and not the temperature of powders, the authors are currently working on the indication of the temperature by well-defined chemical reactions to determine the maximum temperature during milling process and to prove this hypothesis. However, when comparing the expected temperature achieved by ultra-high energy mechanical alloying with the temperature reached on tools by friction during dry machining [12], the expectation might be realistic.

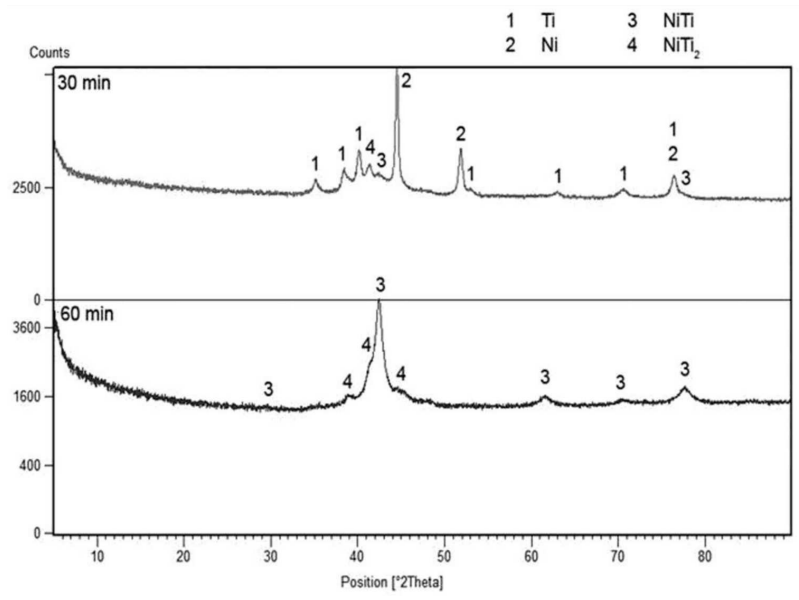

Fig. 3. XRD patterns of mechanically alloyed NiTi46 powder mixture (composition of powders given in wt\%) vs. milling duration.

\section{3. $\mathrm{Fe}-\mathrm{Al}-\mathrm{Si}$ system}

In a more complex alloy system, $\mathrm{Fe}-\mathrm{Al}-\mathrm{Si}$, the ultrahigh energy mechanical alloying results in the mixture of silicides $\left(\mathrm{Fe}_{3} \mathrm{Si}, \mathrm{FeSi}\right)$ and iron aluminide $(\mathrm{FeAl})$, see Fig. 4. The phase composition is different from SHS process, where the $\mathrm{FeSi}, \mathrm{FeAl}$ and $\mathrm{Fe}_{3} \mathrm{Al}_{2} \mathrm{Si}_{3}$ were detected [12]. In order to prove the effect of the friction forces on our mechanical alloying process, the addition of ethanol to the milling vessel as a lubrication agent, and utilization of the Retsch EMAX mill were tested. Results showed that no intermetallics were found after $4 \mathrm{~h}$ of milling, when ethanol was added. The milling in EMAX mill under controlled temperature of the walls also completely supressed the reactions leading to the formation of intermetallics during $4-24 \mathrm{~h}$ milling process (Fig. 4). This result proves the need of the increase of the temperature as a result of the friction during mechanical alloying.

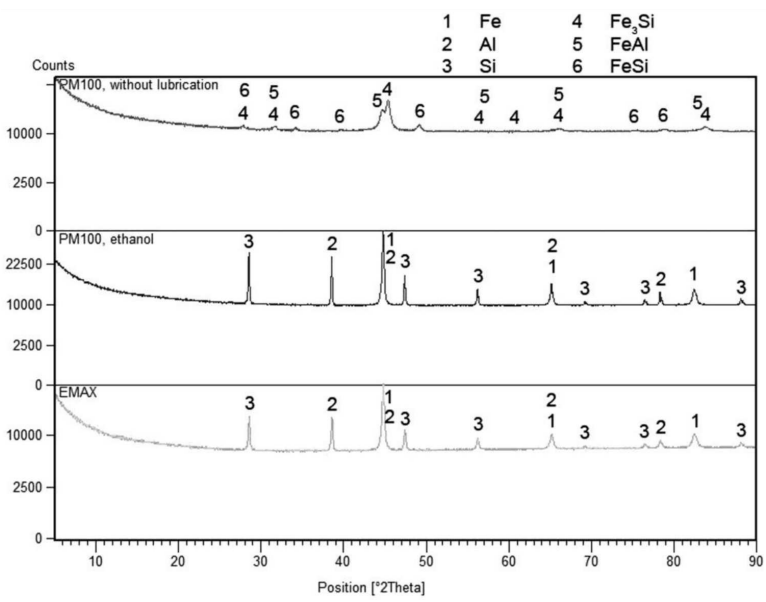

Fig. 4. XRD patterns of mechanically alloyed FeAl20Si20 powder mixture (composition of powders given in wt\%) after milling in conventional planetary ball mill (Retsch PM100) without lubrication, with the addition of ethanol and in Retsch EMAX mill, duration 240 min.

\section{Conclusion}

In this work, the innovative ultra-high energy mechanical alloying process designed by the authors was compared with self-propagating high-temperature synthesis in selected systems ( $\mathrm{Fe}-\mathrm{Al}, \mathrm{Ni}-\mathrm{Ti}, \mathrm{Fe}-\mathrm{Al}-\mathrm{Si})$. There were differences observed between the phases formed in these particular processes. Based on the experiments carried out in this work it can be concluded that:

- In the systems, where SHS reaction is initiated in solid state, the mechanism of SHS and ultra-high energy mechanical alloying is identical. In alloy systems, where liquid initiates the SHS reaction, significant differences were observed.

- The formation of intermetallics in ultra-high energy mechanical alloying process is thermally activated, as well as in SHS.

- When the friction forces, which lead to the heating of the sample, are minimized, the formation of intermetallics is suppressed.

- The temperature achieved in this mechanical alloying process could exceed $600^{\circ} \mathrm{C}$.

Further experiments are planned to determine the maximum temperature of the powder during ultra-high energy mechanical alloying by well-defined chemical reactions. 


\section{Acknowledgments}

This research was supported by the Czech Science Foundation, project 17-07559S.

\section{References}

[1] E. Huttunen-Saarivirta, J. Alloys Comp. 363, 150 (2004).

[2] C.C. Koch, J.D. Whittenberger, Intermetallics 4, 339 (1996).

[3] F.H. Froes, C. Suryanarayana, K. Russell, C.-G. Li, Mater. Sci. Eng. A 192/193, 612 (1995).

[4] T. Mousavi, F. Karimzadeh, M.H. Abbasi, Mater. Sci. Eng. A 487, 46 (2008).

[5] M. Ghadimi, A. Shokuhfar, H.R. Rostami, M. Ghaffari, Mater. Lett. 80, 181 (2012).

[6] P. Novák, T. Kubatík, J. Vystrčil, R. Hendrych, J. Křřž, J. Mlynár, D. Vojtěch, Intermetallics 52, 131 (2014).
[7] P. Novák, P. Pokorný, V. Vojtěch, A. Knaislová, A. Školáková, J. Čapek, M. Karlík, J. Kopeček, Mater. Chem. Phys. 155, 113 (2015).

[8] P. Novák, A. Michalcová, I. Marek, M. Mudrová, K. Saksl, J. Bednarčík, P. Zikmund, D. Vojtěch, Intermetallics 32, 127 (2013).

[9] T.B. Massalski, Binary Alloy Phase Diagrams, ASM, Materials Park 1990.

[10] S. Józwiak, K. Karczewski, Z. Bojar, Intermetallics 18, 1332 (2010).

[11] P. Novák, V. Vojtěch, Z. Pecenová, F. Průša, P. Pokorný, D. Deduytsche, C. Detavernier, A. Bernatiková, P. Salvetr, A. Knaislová, K. Nová, L. Jaworska, Materiali In Tehnologije 51, 679 (2017).

[12] U. Karaguzel, M. Bakkal, E. Budak, Proced. CIRP 46, 173 (2016).

[13] P. Novák, V. Knotek, M. Voděrová, J. Kubásek, J. Šerák, A. Michalcová, D. Vojtěch, J. Alloys Comp. 497, 90 (2010) 